\title{
PREVALENCE OF NECK DISABILITY AMONG DENTAL PROFESSIONALS IN NORTH INDIA
}

Anshul Bansal1, Parul Bansal2, Sandeep Kaur³, Akanksha Malik ${ }^{4}$

\section{HOW TO CITE THIS ARTICLE:}

Anshul Bansal, Parul Bansal, Sandeep Kaur, Akanksha Malik. "Prevalence of neck disability among dental professionals in north India”. Journal of Evolution of Medical and Dental Sciences 2013; Vol. 2, Issue 45, November 11; Page: 8782-8787.

ABSTRACT: AIM: (The aim of this study was to determine the prevalence and severity of neck pain in dentists of north India) [h1]. MATERIALS AND METHODS: Following ethical approval, a cross sectional study was conducted on 74 randomly selected dentists. Questionnaires were used to collect personal and occupational characteristics as well as the prevalence and risk factors of neck pain. Subjects were assessed by visual analogue scale and neck disability questionnaires for pain intensity and functional disability of neck, respectively. RESULTS: Point and last 12 months prevalence of neck pain were $27 \%$ and $76 \%$, respectively. Mean VAS for neck pain is 2.48. CONCLUSION: Results indicated that the prevalence of neck pain and neck disability in dentists appears to be high.

KEYWORDS: Prevalence, visual analogue scale, neck disability index.

INTRODUCTION: Dentist work demands high precision and is often performed with the cervical spine flexed forward and rotated ${ }^{1}$. This induces high static load in the neck region. Prolonged Static load of long duration and repeated movements can result in neck pain, tension neck syndrome, muscle imbalance or cervical instability.

Tension neck syndrome: Tension neck syndrome results in pain, stiffness and tenderness in the neck and trapezius muscles, often with muscle spasms or tender trigger points. These symptoms may not always be localized in the neck; pain can occur between the shoulder blades, radiate down the arms or up into the base of the skull. Headaches also are a common symptom of TNS. Forward head posture is a primary contributing factor to TNS, a problem frequently seen among dentist due to years of poor posture involving holding the neck and head in an unbalanced forward position to gain better visibility during treatment.

Neck pain has been shown to be associated with forward head posture is 20 degree or more for 70 percent of working time. On average, dentist work with forward head posture of at least 30 degree for 85 percent of their time in the operatory ${ }^{2}$. Poor endurance of the neck stabilizing muscles can worsen this pain in occupations where forward head postures are required.

Neutral head posture is ear over shoulder when viewed from the side. Forward head posture occurs when the natural curve at the back of the neck is put out of balance by the sustained weight of the head in the forward position. This can trigger (the strain)[h1] on the neck and upper back structures.

Muscles imbalances: Occupations such as dentistry, where forward head and rounded shoulder postures are common, predispose workers to a unique muscle imbalance that is a primary contributor to TNS, (thoracic)[h1] outlet syndrome and numerous other myofascial pain syndromes. These imbalances develop between the neck and shoulder muscles that stabilize, and those that move. The delivery of dental care requires excellent endurance of the primary shoulder girdle 
stabilizing muscles to perform fine motor skills distally for prolonged period the time. These muscles tend to fatigue quickly and weaken with prolong forward head and rounded shoulder posture.

Cervical instability: Forward head posture can cause cervical instability in cervical spine, and lead to flattening of the neck curve. As muscles, ligaments and tendons stretch, shorten and weaken to adapt to the forward head posture, compression on the discs increases, raising the risk of disk injuries or herniation. Cervical muscles may spasm and become inflamed as they work overtime to hold the head in an unbalanced posture.

Long duration of forward head posture can lead to cervical spondylosis, a degenerative condition involving osteoarthritis of the cervical spine. In several studies conducted on dentist, the cervical vertebrae have actually slipped forward on each other due to this imbalance. A radiographic study revealed that more than half of the dentist had spondylosis of the cervical spine ${ }^{3}$. The condition has numerous potentially disabling effects, the most notable being compression of the spinal cord, leading to pain, numbness and tingling in the arm and hand.

Dentists have a high frequency of neck pain and cervical spondalysis ${ }^{3}$. The objective of the study was to describe and evaluate further the occurrence of musculoskeletal symptoms of neck pain and neck disability among dentist.

MATERIAL AND METHODS: 74 dentists participated in the study. Those who had neck pain before joining the profession were excluded from the study. The participants signed informed consent forms. The study was approved by the ethical committee of the university. Data were collected by means of a special questionnaire (SQ) designed by the research team, and the use of the Neck Pain Disability Index (NPDI) and the Visual Analogue Scale (VAS scores 0-10).

Special Questionnaire Form (SQ): This form consists of demographic details (age, gender, height, body weight, marital status, years at work, physical exercise), four questions about routinely maintained work positions and on durations (i.e., working while sitting and working while standing (min/day), the frequency of breaks /day and break duration (min/day), and the weekly and daily working hours), three questions on the experience of neck pain in specific working positions (i.e. frequency of stiffness of the neck, frequency of neck pain when looking upwards-downwards, frequency of neck pain during work above the level of the head). These questions were scored according to the Likert Scale with 5 points on 'never', rarely', sometimes', 'most times' and 'at all times'.

Neck Pain Disability Index (NPDI): This questionnaire has been widely used and accepted in evaluating the level of disability in patients with neck pain ${ }^{4}$. It consists of 10 parts, seven of which are concerned with daily activities, two parts with pain, and one with concentration problems. Each part presents a choice of 5 scores (0-5), the total score being expressed in terms of percentage of the whole with the high values(representing)[h1] a higher degree of disability.

Visual analogue scale: VAS is the most widely used non verbal self reported scales that measure subject complains of pain 5 . It represent pain complain on a scale of 0 (no pain at all) to 10 (worse pain you have ever felt). Patients were asked to choose one face that best describe how the patient feels, thus describe the intensity of the pain. 
RESULTS: Of the participants in this investigation, 55\% were post graduate students [h1]. 8\% were dentists specialised in the disciplines of orthodontics (9\%), endodontology (9\%), periodontics (3\%), prosthodontics (4\%) and paediatric dentist (1\%) and 7\% were general dentist.

Demographic details (Table 1): 45 participants (61\%) were female and 29 participants (39\%) were male with a mean age of $30 \pm 2$ years (range=24-43 yrs.). Demographic details are presented in Table 1.

Neck pain frequency: The prevalence of neck pain among the participants was $67 \%$ in last 12 months and point prevalence was reported $27 \%$. Prevalence of neck pain in female was $73 \%$ and prevalence in male was reported to be $56 \%$.

Neck disability: Of 74 participants, 42 (56\%) had no disability of the neck, (NDI score 0-4), $27(36 \%)$ had mild disability (NDI score 5-14) and $5(6 \%)$ had moderate (disability (NDI score 1524) of the neck. None of the participant had severe or complete disability (NDI)[h1] score 25).

Relationship of age and frequency of neck pain: Participants were divided into two groups, group 1 include participants from 24years to 33 years. Group 2 include participants from 34 years to 43 years. Prevalence of neck pain in group 1 was $64 \%$ and in group 2 was $76 \%$.prevalence of neck pain was more in older age group but was statistically insignificant.

Frequency of stiffness of the neck, neck pain while looking upward and downward and while working above the level of the head have been shown in figure $1 \mathrm{a}, 1 \mathrm{~b}$ and $1 \mathrm{c}$ respectively.

Comparisons of the experimental parameters and the demographic details on the basis of professional specialization: Dentists were grouped according to the areas of professional specialisation. No differences were found in the data on the experimental parameters on the basis of this grouping.

DISCUSSION: In this study, the frequency and intensity of neck pain and neck disability and its associated factors have been presented. Estimates of prevalence of neck pain in dentists in other studies are high similar to our results ${ }^{6}$. The working positions such as standing or sitting, which the dentist has to maintain during treatment of the patient, can adversely, affect the neck ${ }^{7}$. Investigations using portable ergonomic devices have shown that dentists generally spend half of the working time with their head bent down while sitting, and complain of neck pain ${ }^{8}$. In another study, it has been shown that prolonged working with the neck in flexion in excess of 30 degrees causes neck pain ${ }^{2}$. Although in this study, neck flexion during work (sitting or standing) has been experimentally observed, measurements of the angles have not been made. According to our observations, the neck postures when working at a sitting position were more neutral than those postures while standing. While working in standing position, the neck postures was more asymmetric and at extremes of flexion or in other words, in ergonomically inappropriate positions. In this study it was observed that as the daily and weekly working hours increased, the complaints of neck pain increased. It has been thought that prolonged maintenance of an inappropriate body position while working in a limited area may impose excess loading on the cervical spine. Similar to our study, recent studies have shown no effect of demographic characteristics of dentists on their musculoskeletal complaints9. The NDI scores were found to be higher in the higher age group. This result is similar to those reported by Augustson et $\mathrm{al}^{10}$ and Alexopoulos et al ${ }^{11}$ and can be thought to arise from having worked for longer years in dental practice. In accordance with the results of Alexopoulos et al ${ }^{11}$, in our study also there was no difference among the areas of specialization of the 
dentists in terms of the neck pain. It has been thought that this is due to lack of significant differences between different specialist groups with respect to postures adopted at work, the duration of work and the demographic details. However, a definite generalisation is not possible as the numbers of specialists in each group were not high enough to support such a conclusion. One limitation of this study is the lack of objective measurement methods. Taking video recordings of neck flexion, shoulder elevation, upper extreme abduction, angle of body ante flexion and lateral flexion while the dentist is working, in order to make measurements on the images recorded, should establish the relationship between posture and the presence of neck pain.

Another limitation of the study could be the relatively small numbers of the subjects. It is also thought that individual psychological properties, such as stress intolerance, which would be expected to contribute to incidence and intensity of locomotor pain needs to be included in future studies. Looking at the mean age of the experimental population of this study, significantly young people have been investigated. Inclusion in future research of dentists with much longer background at work should contribute to accumulation of more meaningful and probably more variable results.

CONCLUSION: Dentist have a higher than expected risk for musculoskeletal symptoms in the neck. The probable reason for the high risk is their difficult work positions with cervical spine flexed and rotated, and repetitive precision demanding procedures these work positions can be improved by preventive measures directed towards the workplace, eg, appropriate construction of the dentist's chair, and appropriate design of the work unit, ergonomic education of the dentists and improvement of the work organization.

Acknowledgement: We would like to thank all the participants of the study.

\section{REFERENCES:}

1. Szymanska J. Disorders of the musculoskeletal system among dentists from the aspect of ergonomics and prophylaxis. Ann Agric Environ Med 2002;9: 169-73.

2. Chaffin DB. Localized muscle fatigue-Definition and measurement. J Occup Med 1973; 15: 34654.

3. K, Aitasalo K, Lehtinen R, Pietila J. Skeletal changes in dentist and farmers in Finland. Community dental oral epidemiol1985;13:23-5.

4. Vernon H, Mior S. The Neck Disability Index: A study of reliability and validity. J Manipulative Physiol Ther 1991; 14: 409-15.

5. 5-carlsson AM: Assessment of chronic pain: Aspect of the reliability and validity of the viual analogue scale. Pain 1983;16:87-101.

6. Dyakar MM,Gupta S, Philip G, Pai P. Prevalence of musculoskeletal disorder among dental practitioners. ASL Musculoskeletal Disorders. 2013;1:22-5.

7. Rundcrantz BL. Pain and discomfort in the musculoskeletal system among dentists. Swed Dent J Suppl 1991; 76: 1-102.

8. Rolander B, Karsznia A, Jonker D, Oberg T, Beliner AL. Perceive contra observed physical work load in Swedish dentists. Work 2005; 25: 253-62.

9. Chowanadisai S, Kukiattrakoon B, Yapong B, Kedjarune U, Leggat PA. Occupational health problems of dentists in southern Thailand. Int Dent J 2000; 50: 36-40. 
10. Augustson TE, Marken T. Musculoskeletal problems among dental health personnel. A survey of the public dental health services in Hordaland. Tidsstir Nor Laegeforen 1996; 30: 2776-80.

11. Alexopoulos EC, Stathi IC, Charizani F. Prevalence of musculoskeletal disorders in dentists. BMC Musculoskeletal Disorders 2004; 5: 16.

\begin{tabular}{|l|c|}
\hline Demographic properties and working condition & \\
\hline Total participant Gender & $\mathrm{N}=74$ \\
\hline \multicolumn{1}{|c|}{ Groups } & \\
\hline Male & 29 \\
\hline Female & 45 \\
\hline \multicolumn{1}{|c|}{ Gpecialized Clinical instructors } & 28 \\
\hline Endodontists & 7 \\
\hline Pedodontists & 1 \\
\hline Orthodontists & 7 \\
\hline Oral medicine & 5 \\
\hline Oral pathology & 3 \\
\hline Prosthodontists & 3 \\
\hline Periodontists & 2 \\
\hline Generalized dentist & 5 \\
\hline Post graduate students & 41 \\
\hline Daily working hours mean SD & $9 \pm 1$ \\
\hline Weekly working hours mean SD & $52 \pm 4$ \\
\hline Neck pain VAS mean SD & $5(0-24)$ \\
\hline NPDI score median (min-max) & \\
\hline
\end{tabular}

Table-1: Demographic properties and working condition

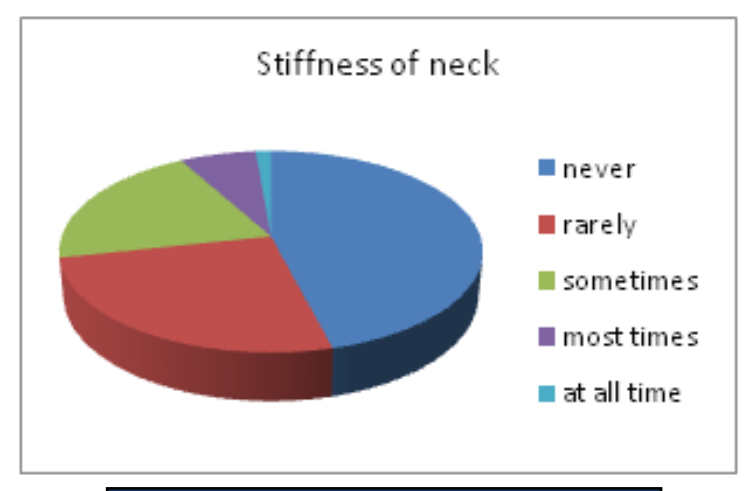

Figure 1a: stiffness of the neck

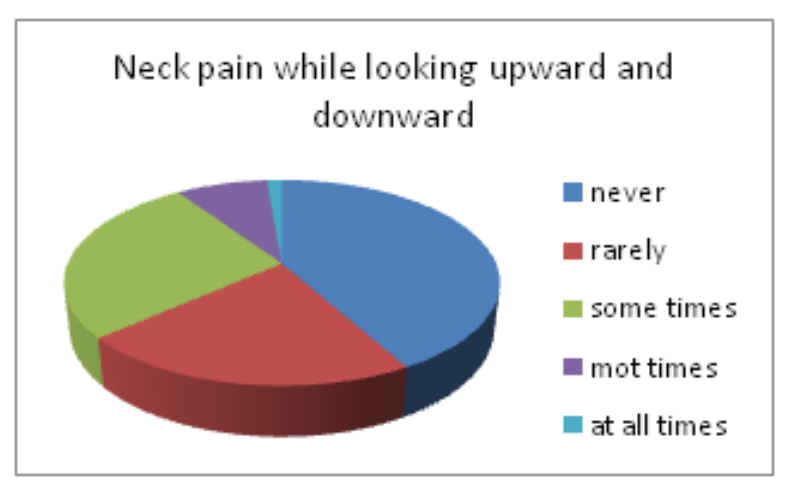

Figure 1b- neck pain while looking upwards and downwards 


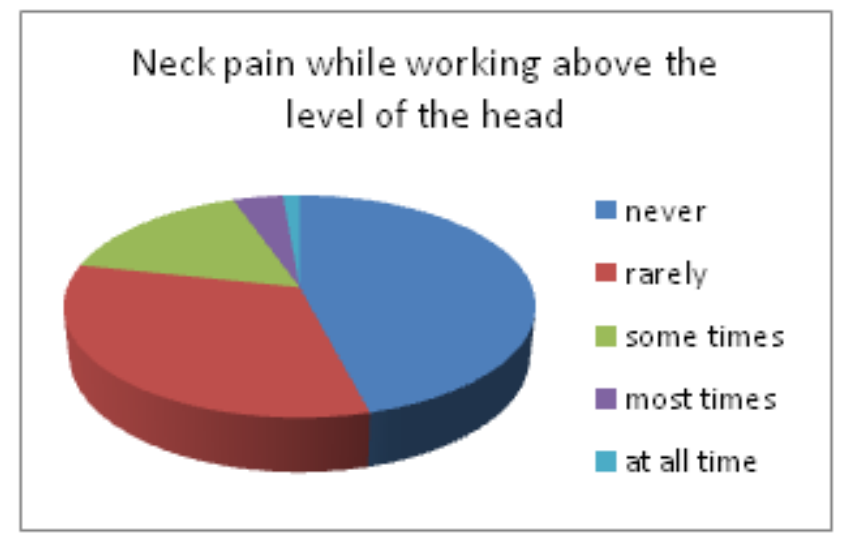

\section{Figure 1c-neck pain while working above the level of the head}

\section{AUTHORS:}

1. Anshul Bansal

2. Parul Bansal

3. Sandeep Kaur

4. Akanksha Malik

\section{PARTICULARS OF CONTRIBUTORS:}

1. Assistant Professor, Department of Otorhinol aryngology and Head Neck Surgery, Adesh Institute of Medical Sciences, Adesh University, Bathinda, Punjab.

2. Reader, Department of Conservative Dentistry \& Endodontics, Subharti Dental College, Swami Vivekanand Subharti University, Meerut, Utter Pradesh (India).

3. Professor, Department of Physiology, Adesh Institute of Medical Sciences, Adesh University, Bathinda, Punjab.
4. Senior Lec turer, Department of Conservative Dentistry \& Endodontics, AMC Dental College, Ahem dabad, Gujarat (India).

\section{NAME ADDRESS EMAIL ID OF THE} CORRESPONDING AUTHOR:

Dr. Anshul Bansal, C/O Mr. Suresh Gupta, 58/6, Jagriti Vihar, Opposite LLRM Medical College, Meerut, Utter Pradesh.

Email - dranshulparul@gmail.com docparulbansal@gmail.com

Date of Submission: 29/10/2013. Date of Peer Review: 30/10/2013. Date of Acceptance: 05/11/2013. Date of Publishing: 06/11/2013 